\title{
The right to health care
}

\begin{abstract}
While our eyes usually glaze over at the continued talk of health care reform, there are a few particulars that bear repeating. So many of the parties involved fail to consider the most basic and most important of all the issues: health insurance is not a luxury, it is a right.
\end{abstract}

At the time of this writing, the tortured and convoluted path of efforts to reform the American health care systems continues. At least one benefit of the seemingly endless Congressional logjam is that it has provided a lengthy opportunity for watercooler discussions and open (albeit sometimes not so friendly) debates. Of course, although we have our own opinions about what the goals of health care reform should be, and how to best accomplish them, in general we can acknowledge the potential validity of alternative positions. But we feel there is one exception, or should be, to our tolerance of different points of view. We simply cannot fathom anything short of universal health insurance coverage, and frankly, with all appropriate respect to our friends, colleagues, and political representatives who believe otherwise, we are clueless as to how they can rationalize their position.

From a strictly consequentialist standpoint, universal health insurance makes sense. At present, nearly 50 million Americans (not counting non-legal residents) lack some type of health care coverage. Many millions more have the most minimal of coverage. Even if one assumes that many of the uninsured nonetheless do receive emergency health care, this is far from ideal. In fact, it is morally pathetic.

Those without insurance do not receive preventive care, seeking treatment only when they fall ill, often times in the most costly of venues - the emergency room. As all physicians know, prophylaxis is gener- ally cheaper, and virtually always more effective, than treatment. This is why we vaccinate the population against infectious diseases, for example. Moreover, when people do not seek or receive appropriate medical care because they lack insurance, ultimately society bears the financial burden anyway. Needless emergency room visits made by the ill who have no other way to obtain health care tax an already overstrained system. Thus, the price of 50 million uninsured is crowded emergency rooms (making it difficult for hospital staff to deal with "real" emergencies); poor health indices; too many preventable deaths; and, among developed nations, higher morbidity and mortality, especially among children and the mentally ill.

Utility is not the only argument for universal health care coverage. Equally compelling is the ethical imperative - the requirement for justice. This nation espouses a belief that there will be liberty, justice, and opportunity for all. Are we succeeding when we deny basic health care coverage to the vulnerable, the frail, or the working poor? And what kinds of opportunity exist for those who cannot walk, eat, drive, or speak because they have suffered strokes, heart attacks, or loss of limbs that could have been prevented with better access to primary and preventive care?

Many object to calls for universal coverage on the grounds of cost, intrusion into freedom of choice, abhorrence of paternalism, and a demand for more individual responsibility, among other reasons. However, we believe that many of those raising these objections in fact already support another system that has many parallels to universal health insurance coverage: universal education.

It is the right of all Americans to obtain a basic education. It is also their responsibility (more accurately, the responsibility of their parents or guardians) to obtain it. One cannot simply "opt out" of being educated, because we as a society consider it, as a matter of utility, too important to have an educated populace. While it is true that we are free to spend more to get better education and while it is also true that many of our public schools are dismal failures, that does not lessen the national commitment we have made to try and ensure that a decent education is available to all.

Is it less important to have a healthy populace? As education clearly confers secondary advantages in job competitiveness and earning potential, we also consider universal education a matter of fairness and justice - we are, after all, the quintessential equal opportunity society. Likewise, we ask, is an equal opportunity to be healthy less of an imperative than an equal opportunity to be educated? We may not agree on how much to spend on heath insurance. And we must concede that health insurance is no guarantee of access to quality health care. But it does not take much of an education to see that leaving 50 million Americans with no health insurance makes no sense.

\section{Laurence A. Turka, Editor in Chief Arthur L. Caplan, Senior Editor}

